\section{References}

1. Carpentier A, Guermonprez JL, Deloche A, Frechette C, DuBost C. The aortato-coronary radial artery bypass graft. A technique avoiding pathological changes in grafts. Ann Thorac Surg. 1973;16:111-21.

2. Gaudino M, Cellini C, Pragliola C, Trani C, Burzotta F, Schiavoni G, et al. Arterial versus venous bypass grafts in patients with in-stent restenosis. Circulation. 2005 30;112(suppl):I265-9.
3. Desai ND, Cohen EA, Naylor CD, Fremes SE. A randomized comparison of radialartery and saphenous-vein coronary bypass grafts. N Engl J Med. 2004;351:2302-9.

4. Collins P, Webb CM, Chong CF, Moat NE. Radial artery versus saphenous vein patency randomized trial: five-year angiographic follow-up. Circulation. 2008;(117):2859-64

5. Buxton BF, Raman JS, Ruengsakulrach P, Gordon I, Rosalion A, Bellomo R, et al Radial artery patency and clinical outcomes: five-year interim results of a randomized trial. J Thorac Cardiovasc Surg. 2003;125:1363-71.

\title{
Cost of thoracic endovascular aortic repair versus open repair and implications for the US health care system
}

\author{
Karen L. Walker, BA, MHS, Paul Lipori, BA, MBA, W. Anthony Lee, MD, and Thomas Mark Beaver, MD, \\ Gainesville, Fla
}

Following the 2005 FDA approval of the TAG endograft (W. L. Gore \& Associates, Inc, Flagstaff, Ariz), thoracic endovascular aortic repair (TEVAR) utilization increased dramatically. ${ }^{1}$ The clinical trial leading to approval of the Gore-TAG thoracic stent graft demonstrated beneficial effects for early morbidity and mortality, with similar longterm survival compared with open repair. ${ }^{2}$ However, there remains a paucity of data comparing the costs of TEVAR versus open repair. This study compared hospital costs and physician relative value units (RVUs) between TEVAR and open repair at a US academic institution.

\section{METHODS}

Records from patients undergoing elective TEVAR and open repair of distal arch and proximal descending thoracic aneurysms between January 2005 and December 2007 at a single academic institution were analyzed. The hospital cost accounting system was used to compare mean costs in the following categories: total hospitalization, total day of surgery, operating room, grafts, anesthesia, imaging, pharmacy, laboratory, and respiratory services. Costs were adjusted to 2007 dollars using the consumer price index. Cost ratios are reported because hospital restrictions prohibited reporting actual values. Age, gender, comorbidities, length of stay (LOS), operating room time, and physician RVUs were examined. Student $t$ test was used for age, RVUs, and cost category variables. Mann-Whitney test was used for median LOS. Pearson chi-square and Fischer exact test were used for gender and comorbidity comparisons (v17.0 SPSS, Chicago, Ill).

\footnotetext{
From the Cardiac Surgery Department, II School of Medicine, University of Rome La Sapienza, Policlinico S. Andrea, Rome, Italy.

Received for publication May 27, 2009; revisions received June 16, 2009; accepted for publication July 5, 2009; available ahead of print Aug 19, 2009.

Address for reprints: Thomas M Beaver, MD, MPH, Associate Professor, Division of Thoracic and Cardiovascular Surgery, University of Florida, PO Box 100286, Gainesville, FL 32610-0286 (E-mail: beavetm@surgery.ufl.edu).

J Thorac Cardiovasc Surg 2010;139:231-2

$0022-5223 / \$ 36.00$

Copyright $(c) 2010$ by The American Association for Thoracic Surgery

doi:10.1016/j.jtcvs.2009.07.020
}

TABLE 1. Patient demographics and comorbidities in comparison groups TEVAR versus open repair

\begin{tabular}{lccc}
\hline & TEVAR & Open repair & $\boldsymbol{P}$ value \\
\hline Age & 73.21 & 62.28 & $<.001$ \\
Female & $42.86 \%(12 / 28)$ & $34.48 \%(10 / 29)$ & .516 \\
Hypertension & $78.57 \%(22 / 28)$ & $89.66 \%(26 / 29)$ & .251 \\
Coronary artery & $32.14 \%(9 / 28)$ & $27.59 \%(8 / 29)$ & .707 \\
$\quad$ disease & & & \\
COPD & $42.86 \%(12 / 28)$ & $20.69 \%(6 / 29)$ & .072 \\
CKD & $0 \%(0 / 28)$ & $17.24 \%(5 / 29)$ & .052 \\
\hline
\end{tabular}

$T E V A R$, Thoracic endovascular aortic repair; $C O P D$, chronic obstructive pulmonary disease; $C K D$, chronic kidney disease.

\section{DISCUSSION}

Twenty-nine patients having open repair and 28 patients having TEVAR were identified. Patients having TEVAR were older, but comorbidities were similar between groups (Table 1). Despite shorter surgical times for TEVAR (168 vs 465 minutes, $P<.001)$, TEVAR operating room costs were 2.03 times greater than open repair $(P<.001)$. Increased operating room costs for TEVAR were secondary to TEVAR graft costs, which were 22.2 times higher than open repair. TEVAR grafts accounted for $74 \%$ of TEVAR day of surgery costs, which were 1.32 times higher than open repair (Figure 1). However, the total hospitalization costs remained 1.55 times greater for open repair versus TEVAR. Longer median LOS for open repair (20 days vs 6 days, $P<.001)$ led to greater utilization of hospital services. Anesthesia costs were 4.00 times greater for open repair versus TEVAR $(P<.001)$. Overall imaging costs were 1.78 times greater for open repair versus TEVAR $(P=$ .023). Pharmacy costs were 5.74 times greater for open repair versus TEVAR $(P=.001)$. Laboratory costs were 4.94 times greater for open repair versus TEVAR $(P<$ .001). Respiratory services were 4.89 times greater for open repair versus TEVAR $(P=.001)$. Despite shorter 


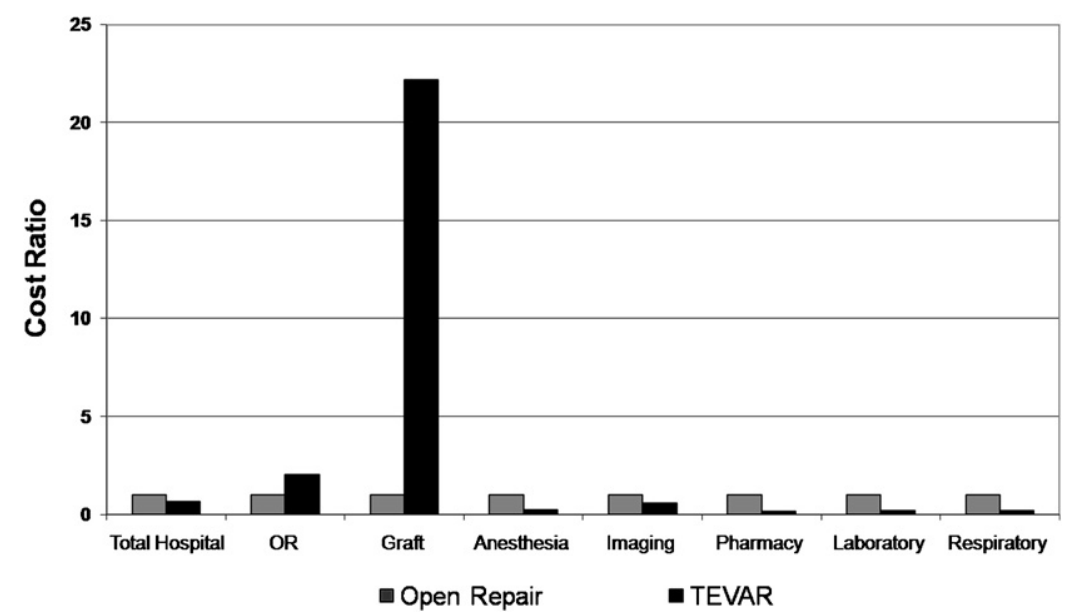

FIGURE 1. Relative cost analysis thoracic endovascular aortic repair (TEVAR) versus open repair. The cost ratio is depicted by having open repair as a control with cost equal to 1 with the relative cost of TEVAR determined by taking the dollar amount for TEVAR and dividing by the dollar amount for open repair. The overall total hospital costs are depicted in the first column with individual service lines depicted across the $\mathrm{x}$-axis.

surgical times, average RVUs were greater for TEVAR versus open repair (97.74 vs 92.97, $P=0.616$ ).

In conclusion, TEVAR day of surgery costs are much greater due to high endograft costs, although overall hospital costs are greater for open repair. Assessment of in-hospital costs reveals TEVAR to be a cost-effective treatment alternative in the short term. The cost-effectiveness of TEVAR should improve if endograft costs decrease with dissemination of this technology. Importantly, this study does not address the long-term costs of TEVAR. TEVAR patients require lifelong monitoring similar to patients having endovascular repair of abdominal aneurysms (EVAR). Analyses of the long-term costs of EVAR are concerning and warrant similar apprehensions for TEVAR. For example, one analy- sis of the 5-year EVAR postprocedural costs revealed a $44 \%$ incremental increase in the global cost compared with the initial implantation cost. ${ }^{3}$ Further investigation of TEVAR long-term costs is imperative for understanding current and future impacts on the US health care system.

\section{References}

1. Orandi BJ, Dimick JB, Deeb GM, et al. A population-based analysis of endovascular versus open thoracic aortic aneurysm repair. J Vasc Surg. 2009;49: 1112-6.

2. Makaroun MS, Dillavou ED, Wheatley GH, Cambria RP. Five-year results of endovascular treatment with the Gore TAG device compared with open repair of thoracic aortic aneurysms. J Vasc Surg. 2008;47:912-8.

3. Noll RE Jr, Tonnessen BH, Mannava K, et al. Long-term postplacement cost after endovascular aneurysm repair. J Vasc Surg. 2007;46:9-15; discussion 15. 